Check for updates

Cite this: Mater. Adv., 2022, 3, 611

Received 27th September 2021, Accepted 12th November 2021

DOI: $10.1039 / \mathrm{d} 1 \mathrm{ma} 00890 \mathrm{k}$

rsc.li/materials-advances

\title{
Effect of conductivity, viscosity, and density of water-in-salt electrolytes on the electrochemical behavior of supercapacitors: molecular dynamics simulations and in situ characterization studies $\nmid$
}

\author{
Débora A. C. da Silva, (D) $\ddagger^{a}$ Manuel J. Pinzón C., $\ddagger^{a}$ Andresa Messias, ${ }^{b}$ \\ Eudes E. Fileti, (D) *c Aline Pascon, (D) a Débora V. Franco, ${ }^{d}$ \\ Leonardo Morais Da Silva*d and Hudson G. Zanin*a
}

\begin{abstract}
We report here molecular dynamics simulations combined with in situ experimental studies to understand the advantages and disadvantages of replacing conventional (salt-in-water, SiWE) aqueousbased electrolytes with very concentrated (water-in-salt, WiSE) systems in supercapacitors. Atomistic molecular dynamics simulations were employed to investigate the energetic, structural, and transport properties of aqueous electrolytes based on sodium perchlorate $\left(\mathrm{NaClO}_{4}\right)$. Simulations covered the concentrations range of $1 \mathrm{~mol} \mathrm{dm}{ }^{-3}\left(1 \mathrm{~mol} \mathrm{~kg}^{-1}\right)$ to $8 \mathrm{~mol} \mathrm{dm}^{-3}\left(15 \mathrm{~mol} \mathrm{~kg}^{-1}\right)$, demonstrating a significant increase in viscosity and density and reduction in ionic conductivity as the concentration reaches the WiSE conditions. A carbon-based symmetric supercapacitor filled with WiSE showed a larger electrochemical stability window (ESW), allowing to span the cell voltage and specific energy. Larger ESW values are possible due to the formation of a solvent blocking interface (SBI). The formation of ionic aggregates owing to the increasing cohesive energy in WiSE disturbs the hydrogen-bond network resulting in physicochemical changes in the bulk liquid phase. In addition, the molal ratio between water and ions is decreased, resulting in a low interaction of the water molecules with the electrode at the interface, thus inhibiting the water-splitting considerably.
\end{abstract}

\section{Introduction}

The growing demand for renewable energy sources has attracted attention to reduce the operational costs regarding the use of electrochemical energy storage devices. ${ }^{1,2}$ In this sense, Li-ion batteries, and supercapacitors (SCs) are widely employed devices for energy storage that are used in different technological applications. These different devices are

\footnotetext{
${ }^{a}$ Advanced Energy Storage Division, Center for Innovation on New Energies Advanced Materials Labs, University of Campinas, Av. Albert Einstein 400, Campinas - SP, 13083-852, Brazil. E-mail: hzanin@unicamp.br

${ }^{b}$ Center of Natural and Human Sciences, Federal University of ABC, 09210-170, Santo André, SP, Brazil

${ }^{c}$ Institute of Science and Technology of the Federal University of São Paulo, 12247-014, São José dos Campos, SP, Brazil. E-mail: fileti@gmail.com

${ }^{d}$ Department of Chemistry, Laboratory of Fundamental and Applied

Electrochemistry, Federal University of Jequitinhonha e Mucuri's Valley, Rodovia MGT 367, km 583, 5000, Alto da Jacuba, 39100-000, Diamantina - MG, Brazil. E-mail: leonardo.morais@ufvjm.edu.br

$\dagger$ Electronic supplementary information (ESI) available. See DOI: 10.1039/ d1ma00890k

\$ These authors contributed equally: Débora A. C. da Silva and Manuel J. Pinzón C.
}

complementary technologies for different applications (e.g., electric vehicles to portable electronics) since batteries have high specific energy while supercapacitors show high specific power characteristics. ${ }^{2-4}$ Nonetheless, the cost-effectiveness of lithium extraction in the earth's crust and the vulnerability it brings to projects in different countries have increased the attention of the scientific community. ${ }^{4-6}$ In this context, alternative technological strategies include the development of Na-ion batteries due to sodium abundance and highperformance aqueous-based supercapacitors which are more environmentally friendly compared to the traditional organicbased devices using toxic solvents. ${ }^{6,7}$ In addition, aqueousbased supercapacitors are an attractive technology due to high ionic conductivity, which decreases the equivalent series resistance $\left(R_{\mathrm{ESR}}\right)$, and the non-flammability characteristics. ${ }^{1}$ The major drawback regarding the use of aqueous-based supercapacitors is the reduced working voltage window (or electrochemical stability window - ESW) that limits the specific energy $E=C U^{2} / 2$, where $C$ is the specific capacitance and $U=\mathrm{ESW}^{5,8,9}$

Several research groups have reported that highly concentrated aqueous-based electrolytes, especially water-in-salt 
electrolytes (WiSE), can mitigate the low energy limitation since the ESW values can be increased by manipulating the electrolyte properties. ${ }^{5,8,10,11}$ Conventional electrolytes (salt-in-water electrolytes, SiWE) used traditionally in energy storage devices have concentrations in the range of $\sim 1$ to $2 \mathrm{~mol} \mathrm{dm}^{-3} \cdot{ }^{12}$ According to Suo et al., ${ }^{12}$ in the case of WiSE, the salt-to-solvent ratio of volume or mass is higher than 1.0. In this sense, highly concentrated electrolytes have strong coordination characteristics that result in a 'blocking ionic effect' at the electrode/solution interface, i.e., the creation of a solvent blocking interface $(\mathrm{SBI})^{13}$ considerably inhibits the water-splitting reaction, leading to larger ESW values. ${ }^{1,10}$ An effective electrolyte concentration affects the maximum cell voltage where the electrolyte is stable due to a complex combination of physicochemical phenomena induced by changes in the ionic strength, osmotic coefficient, and the activation barrier for electron transfer at the electrode/solution interface.

The use of WiSE in SCs induces the presence of 'compensating effects' involving thermodynamic and kinetic components. In brief, the 'salting-out effect' reduces the partial pressure of the dissolved gases $\left(\mathrm{O}_{2}\right.$ and $\left.\mathrm{H}_{2}\right)$ inside the coin cell to values lower than 1.0 bar. As a result, the equilibrium voltage for watersplitting is decreased from its standard value of $1.23 \mathrm{~V}$ predicted by thermodynamics. ${ }^{13,14}$ From the kinetic viewpoint for the electron transfer, the presence of dissipative effects associated with the 'activation overpotential' (Butler-Volmer's model) at the interface (e.g., Helmholtz compact layer) pushes the minimum (theoretical) voltage predicted for water-splitting to higher voltages $^{13}$ due to the presence of an SBI. In this sense, from the kinetic viewpoint, the overpotential for the charge-transfer (watersplitting) reaction can be increased as a function of the electrolyte concentration due to an increase in the amount of specifically adsorbed ionic species that reduces the water activity at the electrode/electrolyte interface.

In the case of the conventional electrolytes denoted as SiWE the water concentration is very high $\left(\approx 55 \mathrm{~mol} \mathrm{dm}^{-3}\right)$. Thus, the solvent dielectric constant in the bulk $\left(\varepsilon_{\mathrm{s}} \approx 78\right.$ at $\left.25{ }^{\circ} \mathrm{C}\right)$ dominates several electrolyte properties influenced by the 'solute activity' $a_{ \pm}=\gamma_{ \pm} \times \mathrm{m} / \mathrm{m}^{\circ}$, where $\gamma_{ \pm}$is the mean ionic activity coefficient, and $m$ is the molality $\left(m / \mathrm{mol} \mathrm{kg}^{-1}\right)$.

As discussed by some authors, ${ }^{14,15}$ to investigate the changes in the transport properties exhibited by some Na-based electrolytes, as in the case of $\mathrm{NaClO}_{4}$ solutions, the non-linear behavior confirmed for the specific conductance and viscosity as a function of the electrolyte concentration could be interpreted assuming that the ionic species approached a distribution characteristic of crystal hydrate at high concentrations, i.e., near saturation conditions. In this sense, the aqueous quasi-lattice model discussed by Braunstein $^{16}$ is essentially one of competing associations and hydration equilibria and is similar to the model proposed by Stokes and Robinson ${ }^{17}$ as an extension of the Debye-Hückel theory to concentrated solutions. In the case of WiSE, the distinction between solvent and solute is not straightforward since the ionic concentration is not so different from the water concentration. Also, due to the hydration phenomenon, each dissolved ionic species captures several water molecules in its solvation shell, i.e., the effective concentration of the 'almost free' water molecules not involved in the hydration process is very limited. As a result, solute and solvent properties are both important for WiSE.

Several studies have reported the expansion of the ESW using highly concentrated aqueous electrolytes based on Na-ions such as NaFSI, ${ }^{18}$ NaOTF-TEAOTF, ${ }^{19}$ NaOTF, ${ }^{20}$ and $\mathrm{NaClO}_{4}{ }^{8}$ Among them, sodium perchlorate $\left(\mathrm{NaClO}_{4}\right)$ has presented high performance and large ESW values. Nakamoto et al. ${ }^{8,21}$ reported high ionic conductivity $\left(108 \mathrm{mS} \mathrm{cm}^{-1}\right)$ and the expansion of ESW from $1.2 \mathrm{~V}$ to $2.8 \mathrm{~V}$ after increasing the sodium perchlorate concentration. Generally, WiSE permits to span the ESW values with changes in the intrinsic conductivity and a strong tendency to crystallization at the interface of the dissolved ionic species. ${ }^{22}$ For a particular electrolyte, intrinsic properties such as diffusivity, conductivity, and viscosity are also different for SiWE and WiSE systems. ${ }^{10}$ Therefore, the study of the molecular and transport properties exhibited by WiSE is crucial for a better understanding of the overall electrochemical behavior verified for WiSE-based SCs.

Although Sakamoto et al. 5,8,21 have reported the 'static structure' of highly concentrated $\mathrm{NaClO}_{4}$ aqueous electrolytes, few detailed studies could be found in the literature on the molecular structure and dynamics of the ions in WiSE. In this sense, new studies regarding the $\mathrm{NaClO}_{4}$ electrolyte system are necessary for a better understanding of their physicochemical properties. In this work, the structural properties and the transport characteristics of the $\mathrm{NaClO}_{4}$ - based electrolyte at various concentrations are studied using atomistic molecular dynamics (MD) simulations. Additionally, experimental findings considering the behavior of the WiSE-based SCs were used to support the MD results.

\section{Methodological section}

\subsection{Computational details}

In this work the molecular properties of sodium perchlorate aqueous solutions in three and two concentrations for the SiWE $\left(1,2\right.$, and $\left.5 \mathrm{~mol} \mathrm{dm}^{-3}\right)$ and WiSE (7 and $8 \mathrm{~mol} \mathrm{dm}^{-3}$ ) systems are studied, respectively. For convenience, the conversion between molar $\left(\mathrm{c} / \mathrm{mol} \mathrm{dm}^{-3}\right)$ and molal $\left(\mathrm{m} / \mathrm{mol} \mathrm{kg}^{-1}\right)$ concentrations is presented in Table 1 . The conversion between molality $(m)$ and molarity $(c)$ is given by the formula $m=$ $(1000 \times c) /\left(\left(1000 \times \rho_{\text {solution }}\right)-(c \times W)\right)$, where $W$ is the salt molecular mass. By definition, in this work, the SiWE and WiSE systems regarding the $\mathrm{NaClO}_{4}$ solutions are those with concentrations below and above $8.2 \mathrm{~mol} \mathrm{~kg}{ }^{-1}$, respectively. ${ }^{10}$ All configurations were assembled using the PACKMOL package considering a cubic box with edges of $3.5 \mathrm{~nm}^{23}$ (please see Fig. 1).

All potential models used to describe intermolecular interactions were based on the OPLS-AA force field. ${ }^{24}$ The water molecule was treated using the TIP4/2005 model, ${ }^{25}$ while the atomic partial charges and Lennard-Jones parameters of $\mathrm{ClO}_{4}{ }^{-}$ ions were taken from the parametrization analysis using the 
Table 1 Simulation details regarding the composition of the investigated electrolyte systems

\begin{tabular}{llccccc}
\hline Molarity $\left(\mathrm{mol} \mathrm{dm}^{-3}\right)$ & Molality $\left(\mathrm{mol} \mathrm{kg}^{-1}\right)$ & Ion Na & Ion $\mathrm{ClO}_{4}$ & Water molecules & Total interaction sites & Mass ratio $\left(m_{\text {salt }} / m_{\text {solvent }}\right)$ \\
\hline 1 & 1 & 20 & 20 & 1100 & 4520 & 0.12 \\
2 & 2 & 36 & 36 & 1000 & 4216 & 0.24 \\
5 & 7 & 89 & 89 & 990 & 4494 & 0.86 \\
7 & 12 & 119 & 119 & 945 & 4494 & 1.47 \\
8 & 15 & 133 & 925 & 4498 & 1.84
\end{tabular}
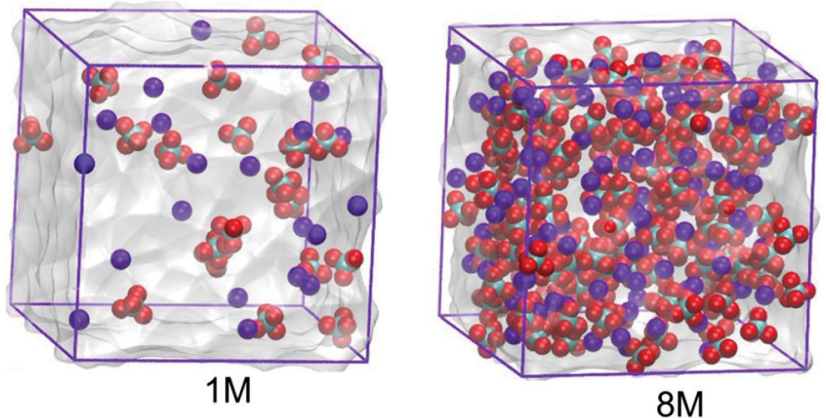

Fig. 1 Molecular configurations of the $1.0 \mathrm{~mol} \mathrm{dm}^{-3}$ and $8.0 \mathrm{~mol} \mathrm{dm}^{-3}$ $\mathrm{NaClO}_{4}$ aqueous electrolytes. The anions are given in green and red while the cations are presented in blue.

RESP-A1A (HF/6-31G*) charge model. ${ }^{26,27}$ The Lennard-Jones parameters and atomic charges on the ions are listed in Table S1 (ESI $\dagger$ ).

The equilibration of the electrolyte solutions was carried out in an isothermal-isobaric ensemble (NPT) for $10 \mathrm{~ns}$, and the trajectory production was performed using the canonical ensemble $(N V T)$ for 100 ns under normal conditions $(T=$ $298 \mathrm{~K}$ and $p=1 \mathrm{~atm})$. A Parrinello-Rahman barostat ${ }^{28}$ was utilized to maintain the constant pressure with a time constant of $2 \mathrm{ps}$ and compressibility constant of $5 \times 10^{-5} \mathrm{bar}^{-1}$. To ensure a constant temperature, a Nosé-Hoover thermostat ${ }^{29}$ was used with a time constant of 2 ps. The Lennard-Jones interaction computed by the classical shifted force technique and long-range electrostatic correction estimated by the Particle-Mesh-Ewald method (PME) ${ }^{30}$ were applied beyond a cutoff radius of $0.9 \mathrm{~nm}$. Periodic boundaries were employed in all directions. The integration time-step was $2.0 \mathrm{fs}$, and the coordinates and thermodynamic properties were stored every $0.1 \mathrm{ps}$. Table 1 shows the details of the investigated solutions.

Extended MD trajectory simulations were applied to obtain satisfactory accuracy for the electrolyte transport properties studied in this work. The standard deviation was assessed by dividing the trajectory into smaller blocks. 10 ns blocks were used for diffusion coefficients, while $30 \mathrm{~ns}$ blocks were considered for ionic conductivity analysis. The final values were obtained as the overall mean block and their corresponding standard deviations. All simulations were performed using the molecular dynamics GROMACS 2020 package. $^{31}$

\subsection{Experimental details}

2.2.1. Preparation of buckypaper electrodes using MWCNTs. The MWCNT electrodes were manufactured based on the procedure described in a previous work. ${ }^{32}$ Briefly, $80 \mathrm{mg}$ of multi-walled carbon nanotubes (CNT Co., Ltd) was dispersed in $400 \mathrm{~mL}$ of deionized water, with the addition of $500 \mathrm{mg}$ of sodium dodecyl sulfate surfactant (Merck). The mixture was treated for 45 min using a tip sonication system to obtain a stable dispersion of MWCNTs. Subsequently, the solution was vacuum filtered using a Büchner-type ceramic funnel filter, a polymeric PVDF filtration membrane, and a Kitasato. After $60 \mathrm{~min}$, the MWCNTs formed a buckypaper structure, which was cut into discs of $10 \mathrm{~mm}$ in diameter with an average mass of $6 \mathrm{mg}$ (please see Fig. 2a).

2.2.2. Preparation of electrolytes. Electrolyte solutions were prepared using sodium perchlorate salt (ACS reagent, $\geq 98.0 \%$ ) purchased from Sigma-Aldrich. For preparation of all solutions, deionized Milli-Q water $\left(18 \mathrm{M} \Omega \mathrm{cm}^{-1}\right)$ was used.

2.2.3. Fabrication of a coin cell device. The symmetric supercapacitors were assembled in the coin-cell configuration using a model CR2032 standard system using two similar MWCNT electrodes. A model TF4850 (NKK) paper used as the separator was soaked with $60 \mu \mathrm{L}$ of electrolyte. The different coin cell elements are shown in Fig. $2 b$.

2.2.4. Ex situ characterization of the electrode material and electrolyte. Scanning electron microscopy (SEM) analysis of the MWCNT samples was accomplished using a Thermo Fisher Quattro microscope from FEG. A secondary electron detection mode (Everhart-Thornley Detector) with a potential of $20 \mathrm{kV}$ and a horizontal field width (HFW) of $17 \mu \mathrm{m}$ was used throughout. Raman analysis of electrodes was performed using a Renishaw inVia spectrometer. A $1.58 \mathrm{eV}$ near-infrared laser line was used together with a $50 \times$ lens, with $60 \mathrm{~s}$ of exposure time, two accumulations, and $50 \%$ of the total laser power
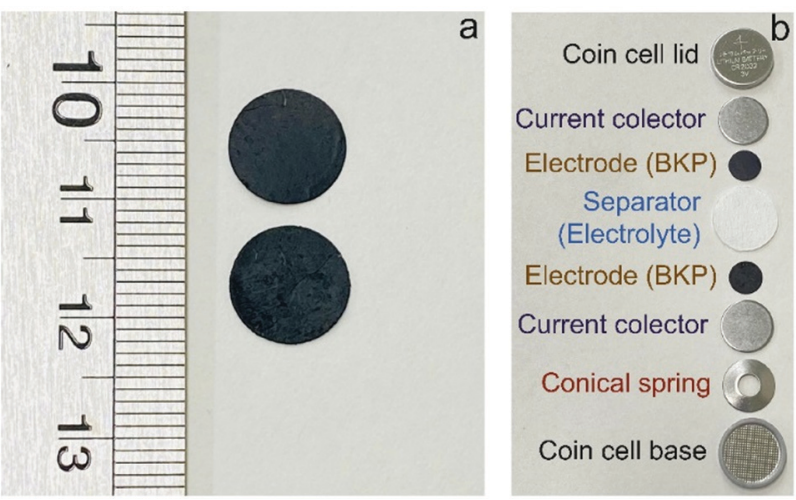

Fig. 2 (a) Self-supporting MWCNT electrodes. (b) Components of a symmetric supercapacitor assembled using a model CR 2032 coin cell filled with the SiWE $\left(7 \mathrm{~mol} \mathrm{~kg}^{-1}\right)$ or WiSE $\left(15 \mathrm{~mol} \mathrm{~kg}^{-1}\right) \mathrm{NaClO}_{4}$ solutions. 
( $\sim 150 \mathrm{~mW})$. Calibration was carried out using a standard silicon sample $\left(520.5 \mathrm{~cm}^{-1}\right)$. For the Raman analysis of the electrolytes, the aforementioned equipment was used with a $1.96 \mathrm{eV}$ laser and $\sim 84 \mathrm{~mW}$ power, through a $20 \times$ lens, taking two accumulations each with an exposure time of 40 seconds.

\subsection{Electrochemical (in situ) experiments using different electrolytes}

2.3.1. Determination of the electrochemical stability window (ESW). Symmetric supercapacitors assembled using the different aqueous sodium perchlorate electrolytes (SiWE and WiSE systems) were electrochemically characterized to complement the computational findings. The CR2032 coin cells containing the different electrolytes were assembled using the buckypaper MWCNT electrodes. Different electrochemical studies were carried out using cyclic voltammetry (CV), singlestep chronoamperometry (SSC), and electrochemical impedance spectroscopy (EIS) techniques. The maximum value of the electrochemical stability window (ESW) for each electrolyte, the equivalent series resistance $\left(R_{\mathrm{ESR}}\right)$, the specific (gravimetric) capacitance $\left(C_{\mathrm{s}}\right)$, energy density $\left(E_{\mathrm{s}}\right)$ and power density $\left(P_{\mathrm{s}}\right)$ were determined. The experimental protocol reported by Nunes et $a l .{ }^{33}$ was applied in this work.

Cyclic voltammetry. A rough estimation of the ESWs for SiWE and WiSE systems was initially obtained from the CV experiments accomplished at $1.0 \mathrm{mV} \mathrm{s}^{-1}$ covering the voltage range of 1.21.7 V. After this, complementary SSC and EIS experiments were carried out to accurately determine the maximum ESWs attained for each electrolyte in the absence of water-splitting.

Single-step chronoamperometry. SSC experiments based on the Heaviside's step function ${ }^{34}(U(t)=0$ for $t \leq 0$ and $U(t)=\mathrm{ESW}$ for $t>0$ ) were conducted for $60 \mathrm{~s}$, covering the voltage range of 1.2-1.7 V. Thus, considering the series canonic circuit model $\left(R_{\mathrm{ESR}}-C_{\mathrm{DLC}}\right)$ for well-behaved EDLCs, the transient current response is given by the relation $I_{\mathrm{c}}=I_{(t \rightarrow 0)} \times \exp (-t / \tau)$, where $I_{(t \rightarrow 0)}=\left(\delta U / R_{\mathrm{ESR}}\right)$ is the current expected after application of the H-step voltage perturbation $(\delta U)$, and $\tau=R_{\mathrm{ESR}} \times C_{\mathrm{DLC}}$ is the time constant. Conversely, a faradaic current $\left(I_{\mathrm{f}}\right)$ due to an irreversible electrode reaction (e.g., water-splitting) is governed by Faraday's law, i.e., without a transient behavior, since $I_{\mathrm{f}} \cong$ constant for a particular $U$-value. Therefore, a background (parasitic) current, after ca. 10-30 s in the SSC experiments, commonly indicates electrolyte decomposition. Even so, in some cases, additional experiments using the impedance technique may be necessary to confirm the occurrence of water-splitting.

Electrochemical impedance spectroscopy. EIS experiments are highly sensitive for detecting the presence of very small faradaic currents corresponding to a charge-transfer resistance $\left(R_{\mathrm{CT}}\right)$. Therefore, impedance data were obtained by applying a $10 \mathrm{mV}$ (peak-to-peak) amplitude covering the frequency range of 10 $\mathrm{kHz}$ to $10 \mathrm{mHz}$. The d.c. voltages $(U=1.2-1.7 \mathrm{~V})$ were the same used in the CV and SSC experiments. In the presence of watersplitting, the interface phenomenon is represented by the Randles simplified equivalent circuit $\left(R_{\mathrm{ESR}}-\left[R_{\mathrm{CT}} \| C_{\mathrm{DLC}}\right]\right)$, where the equivalent series resistance $\left(R_{\mathrm{ESR}}\right)$ appears in series with the parallel combination between the double-layer capacitance $\left(C_{\mathrm{DLC}}\right)$ and the charge-transfer resistance $\left(R_{\mathrm{CT}}\right)$. Instead of a 'straight line' represented by $R_{\mathrm{ESR}}-C_{\mathrm{DLC}}$, the former model predicts a poorly developed semicircle in the low-frequency range of the complex plane while a very high $R_{\mathrm{CT}}$ value corresponds to the parasitic current.

\subsubsection{Determination of capacitance, energy and power}

Galvanostatic charge-discharge. GCD experiments were conducted by applying specific (gravimetric) currents in the range of 0.25 to $4 \mathrm{~A} \mathrm{~g}^{-1}$. The voltage range used in the GCD experiments corresponded to the ESW values obtained in the SSC and EIS experiments (see the Results and discussion section). In this sense, the following equations were used to calculate the specific capacitance $\left(C_{\mathrm{g}}\right)$, energy density $\left(E_{\mathrm{s}}\right)$, and power density $\left(P_{\mathrm{s}}\right):^{35,36}$

$$
C_{\mathrm{g}}=I /(m \times(\mathrm{d} U / \mathrm{d} t))
$$

where $I$ is the cathodic (discharge) current in milliamperes, $m$ is the active mass present on both electrodes in milligrams, and $\mathrm{d} U / \mathrm{d} t$ is the discharge curve slope in Volts per second.

$$
\begin{gathered}
E_{\mathrm{S}}=\left(C_{\mathrm{g}} \times(\mathrm{ESW})^{2}\right) / 7.2 \\
P_{\mathrm{s}}=\left(E_{\mathrm{S}} \times 1800\right) /\left(C_{\mathrm{g}} \times \mathrm{ESR} \times m\right)
\end{gathered}
$$
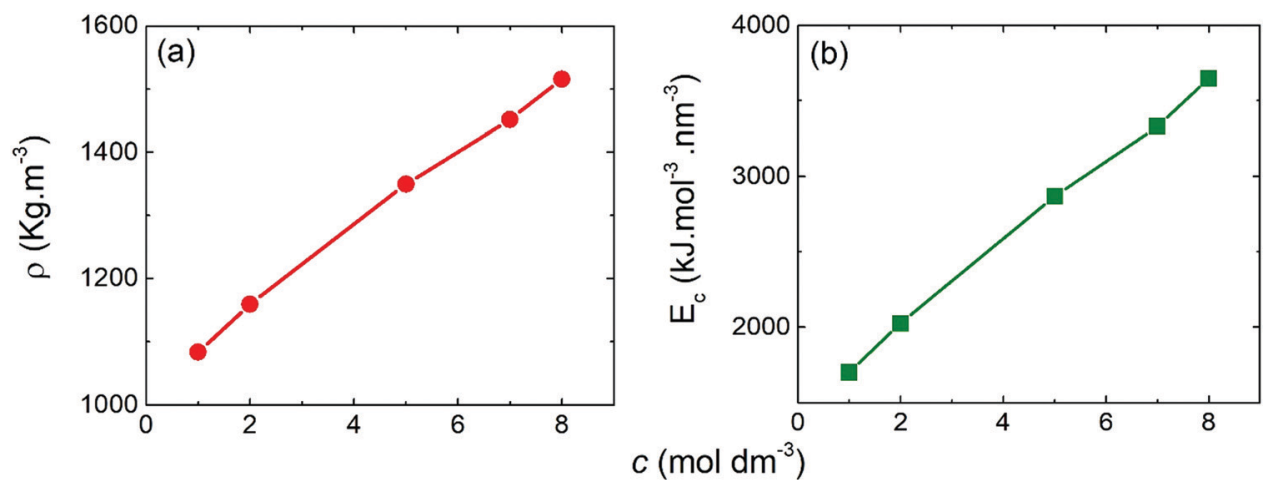

Fig. 3 Mass density (a) and cohesive energy (b) determined from the MD simulations as a function of the molar concentration of the $\mathrm{NaClO}_{4}$-based electrolyte. 
The ESR values were determined from the GCD data using the relation $R_{\mathrm{ESR}}=\Delta U_{\mathrm{drop}} / 2 I .{ }^{36}$ All electrochemical measurements were performed using a model BSC-810 potentiostat cycler system from BioLogic ${ }^{\circledR}$.

\section{Results and discussion}

\subsection{MD simulations}

3.1.1. Energetic properties. The SiWE and WiSE solutions have very different molecular structures and compositions. This difference becomes evident when we compare their densities and cohesive energies. Fig. 3(a) presents mass density as a function of the molar concentration. As expected, as the concentration increases, the mass density of the electrolytes increased linearly from $1083 \mathrm{~kg} \mathrm{~m}^{-3}(1 \mathrm{M})$ to $1516 \mathrm{~kg} \mathrm{~m}^{-3}(8 \mathrm{M})$. The same linear trend was observed for cohesive energy. These densities are in agreement with the literature reports. ${ }^{10,27}$ From intuitive thoughts based on experimental findings, a high electrolyte viscosity may affect ionic mobility, reducing electrolyte conductivity (please see further discussion on Transport properties) and ion penetration in the interconnected meso- and micro-pores structures of the electrode. ${ }^{37}$

The total intermolecular interactions in solution are quantified by the cohesive energy $\left(E_{\mathrm{c}}\right)$, which was computed through the ratio between the internal energy of vaporization $\left(\Delta U_{\text {vap }}\right)$ and the liquid molar volume $\left(V_{\mathrm{m}}\right):^{38,39}$

$$
E_{\mathrm{c}}=\left(\Delta U_{\text {vap }}\right) / V_{\mathrm{m}}
$$

For energy of vaporization, we considered only the intermolecular interactions. Similarly to mass density, the cohesive energy increased with molar concentration, presenting higher values for WiSE than SiWE. This result may be associated with the greater number of $\mathrm{ClO}_{4}^{-}$anions present in WiSE. As reported by Yin et al., ${ }^{40-42}$ the anion $\mathrm{ClO}_{4}^{-}$produces a structure-breaking effect, which breaks the hydrogen bond network between the water molecules, but forms new ones between anions and water. This effect increases the internal energy of vaporization of the electrolyte and, consequently, its cohesive energy. ${ }^{39}$ For practical devices used in electric vehicles or mobile devices, for instance, electrochemical cells may have operational conditions above $40{ }^{\circ} \mathrm{C}$, which usually reduces energy efficiency considerably. That is why high cohesive energy is desirable for better thermal stability. ${ }^{43,44}$

The density of hydrogen bonds (\#HB's) was determinate by the average number of $\mathrm{O} \cdots \mathrm{H}$ hydrogen bonds per volume for the different $\mathrm{NaClO}_{4}$ molar concentrations. For both solutions, SiWE and WiSE, the density of hydrogen bonds formed between water molecules (e.g., $\mathrm{H} \cdots \mathrm{O}_{\mathrm{W}}$, red curve) is more significant than between water and anions (e.g., $\mathrm{H} \cdots$ OCl, blue curve), as shown in Fig. 4.

Note that the total density of hydrogen bonds (black curve) decreases with concentration, following the increase of cohesive energy (please see Fig. 3(b)). The higher concentration of ions leads to a drastic increase in electrostatic interactions in the bulk, which dominate the intrinsic energy of WiSE. Table 2

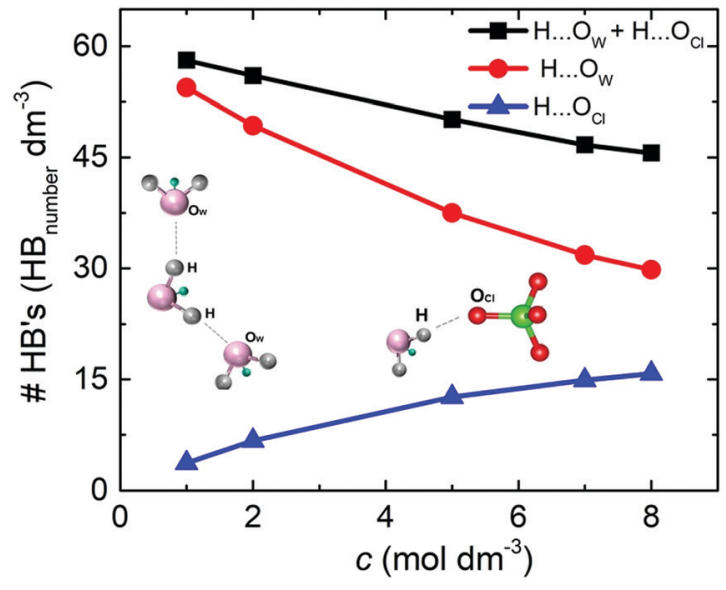

Fig. 4 Density of hydrogen bonds ( $\mathrm{HB}$ 's) as a function of the $\mathrm{NaClO}_{4}$ molar concentration. The blue curve stands for $\mathrm{H} \cdots \mathrm{O}_{\mathrm{Cl}}$ pairs $(\boldsymbol{\Delta})$, the red curve for $\mathrm{H} \ldots \mathrm{O}_{\mathrm{w}}$ pairs $(\mathbf{O})$, and the black curve $(\boldsymbol{\square})$ is the sum of both pairs.

Table 2 Coulombic and van der Waals components of the cohesive energy for the $\mathrm{NaClO}_{4}$ solutions at different molar concentrations

\begin{tabular}{llll}
\hline$c / \mathrm{mol} \mathrm{dm}^{-3}$ & $\begin{array}{l}E_{\text {Coul. }} / \\
\mathrm{kJ} \mathrm{mol}^{-1} \mathrm{~nm}^{-3}\end{array}$ & $\begin{array}{l}E_{\mathrm{vdw}} / \\
\mathrm{kJ} \mathrm{mol}^{-1} \mathrm{~nm}^{-3}\end{array}$ & $\begin{array}{l}E_{\mathrm{c}} / \\
\mathrm{kJ} \mathrm{mol}^{-1} \mathrm{~nm}^{-3}\end{array}$ \\
\hline 1 & -2234 & 283 & -1951 \\
2 & -2553 & 272 & -2281 \\
5 & -3380 & 243 & -3137 \\
7 & -3832 & 228 & -3603 \\
8 & -4104 & 190 & -3914
\end{tabular}

presents the decomposition of cohesive energy $\left(E_{\mathrm{c}}\right)$ into its coulombic $\left(E_{\text {Coul. }}\right)$ and van der Waals $\left(E_{\mathrm{vdW}}\right)$ components. As the concentration rises, the increase in coulombic contribution in magnitude is observed, as well as decrease in the van der Waals component. In all the cases, the increase in coulombic energy dominates the cohesive energy. One issue here is that the formation of $\mathrm{NaClO}_{4}$ in solution or at the electrode/electrolyte interface affects the electrolyte interaction with the electrode. Increasing coulomb forces will reduce ionic mobility, and salt adsorption at the electrode/electrolyte interface forms the solvent blocking interface (SBI). ${ }^{13}$ The latter phenomenon was briefly mentioned in the Introduction section, i.e., an SBI can be responsible for the charge-transfer hindrance related to water-splitting during cell polarization at high voltages (see further discussion in this work).

3.1.2. Structural properties of SiWE and WiSE. The radial distribution function (RDF) of the center of mass of pair correlation is a function that describes how density varies as a function of distance from a reference particle. It also indirectly assesses the interactions between ions and molecules present in electrolytes. Fig. 5(a) shows the pair correlation functions of $\mathrm{Na}$-water. The first peak of $\mathrm{RDF}$ around the $\mathrm{Na}^{+}$ ion occurs at $0.24 \mathrm{~nm}$ with a narrow and intense shape, indicating a well-defined orientation of the water molecules in the first hydration shell. ${ }^{45}$ The reduction in the first peak of 

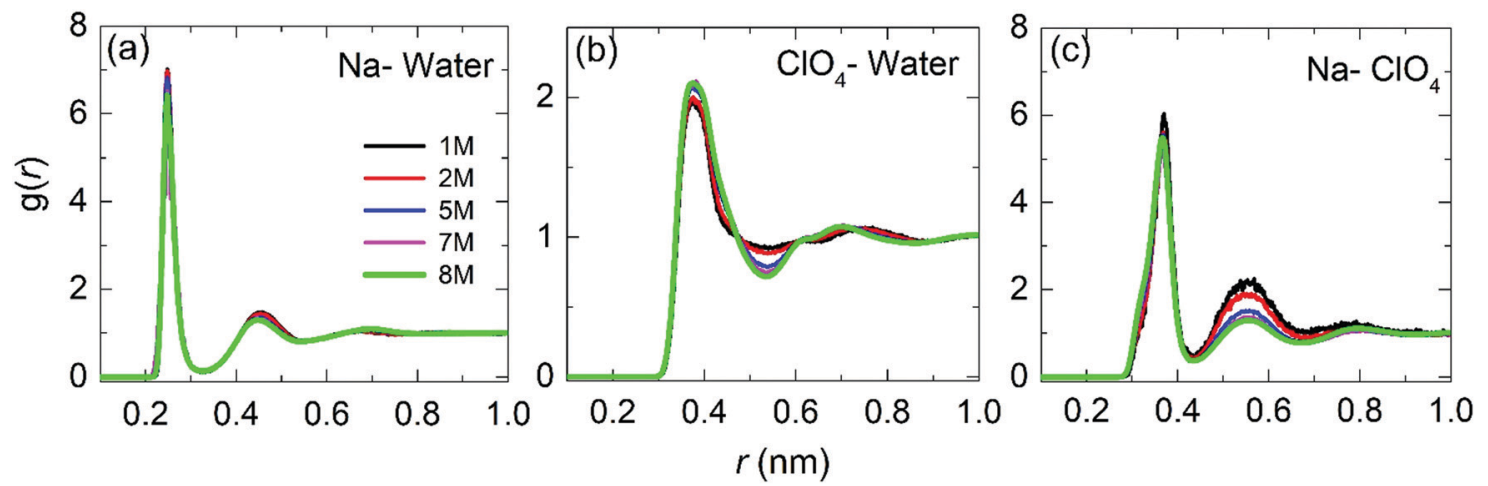

Fig. 5 Radial distribution functions for the center-of-mass for $\mathrm{Na}$-water, $\mathrm{ClO}_{4}$-water and $\mathrm{Na}-\mathrm{ClO}_{4}$ as a function of the molar concentration.

RDF correlates with the reduction of $\mathrm{Na}$-water pairs with increase in concentration. It can be noted, that the profiles of hydration shell do not present sensibility to the increase of the salt concentration, which is in good agreement with the previously reported findings. ${ }^{5,46}$ The radius of the first hydration shell at the first minimum is $0.33 \mathrm{~nm}$. The coordination number of the first shell for all concentrations is shown in Table 3. Note that the coordination number of 5.6 obtained at $1 \mathrm{M}$ is $\sim 24 \%$ higher compared to the corresponding value of 4.3 verified at $8 \mathrm{M}$. This behavior may be attributed to the low molar ratio of the super-concentrated (WiSE) solution since there are fewer available water molecules for ion hydration. The second peak in Fig. 5(a) is less intense and defined with a maximum at $0.45 \mathrm{~nm}$, and a second minimum at $\sim 0.55 \mathrm{~nm}$ can also be identified.

Fig. 5(b) shows the RDF for $\mathrm{ClO}_{4}$-water. The maximum of the first peak is observed at $\approx 0.37 \mathrm{~nm}$, with the first and second minima at $0.54 \mathrm{~nm}$ and $0.88 \mathrm{~nm}$, respectively. Peak positions and heights are in agreement with the literature reports. $^{26,45,47}$ It can be observed that as the concentration increases, the height of the first peak and the depth of the first minimum also increases, indicating a more significant structuring in WiSE than in SiWE (normal) electrolytes.

Finally, Fig. 5(c) shows the RDF for $\mathrm{Na}-\mathrm{ClO}_{4}$ pairs. The radius of the first hydration shell identified as the $\mathrm{RDF}$ minimum is $0.43 \mathrm{~nm}$. From the second peak at $0.55 \mathrm{~nm}$, it can be asserted that the increased number of anions in the second hydration shell makes it more diffusive. In addition, the number of $\mathrm{ClO}_{4}{ }^{-}$anions in the first hydration shell increased from 0.4 at $1 \mathrm{M}$ to 2.0 at $8 \mathrm{M}$. The increase of the coordination number verified for the $\mathrm{Na}_{-}-\mathrm{ClO}_{4}$ pairs indicates a strong association between $\mathrm{Na}^{+}$and $\mathrm{ClO}_{4}{ }^{-}$.

Table 3 Coordination number for $\mathrm{Na}$-water, $\mathrm{ClO}_{4}$-water and $\mathrm{Na}-\mathrm{ClO}_{4}$ as a function of the electrolyte concentration

\begin{tabular}{llll}
\hline$c / \mathrm{mol} \mathrm{dm}^{-3}$ & $\mathrm{Na}$-water & $\mathrm{ClO}_{4}$-water & $\mathrm{Na}-\mathrm{ClO}_{4}$ \\
\hline 1 & 5.6 & 19.8 & 0.4 \\
2 & 5.5 & 19.5 & 0.6 \\
5 & 4.7 & 17.8 & 1.3 \\
7 & 4.4 & 16.8 & 1.7 \\
8 & 4.3 & 16.8 & 2.0
\end{tabular}

A complementary electrolyte structural analysis can be done in terms of the spatial distribution function (SDF). This analysis covers the radial and angular coordinates of the interatomic distance vector. It can precisely describe the three-dimensional density distribution of a solvent in a local coordinate system attached to a solute molecule. Here, in terms of SDF, the threedimensional solvation structure for the water and cations around the $\mathrm{ClO}_{4}{ }^{-}$anions was calculated according to Brehm et al. ${ }^{48,49}$ Fig. 6 shows the isosurfaces for the sodium cations and the water molecules distributed around the $\mathrm{ClO}_{4}{ }^{-}$anion.

In general, cations present around the anions are much more pronounced compared to water molecules. In addition, one can see the complementary character of the two SDFs obtained for water and cations. Cations are distributed directly in front of each oxygen atom, forming four very different caps, and water molecules come to occupy the interstitial space of this distribution. It can also be seen that the spatial density distribution for the cations increases with the concentration from 1 to $8 \mathrm{M}$. On the contrary, the water distribution follows an opposite trend. This result is related to the coordination number of the water molecules, which decreases around the $\mathrm{ClO}_{4}{ }^{-}$anion with increasing concentration (see Table 3). SDF of $\mathrm{Na}^{+}$ions shows clear coordination around the $\mathrm{ClO}_{4}{ }^{-}$anion, indicating a strong association between the ionic pairs. It can be seen that the water molecules and $\mathrm{Na}^{+}$ions were tetracoordinate to the $\mathrm{ClO}_{4}{ }^{-}$ion for the different $\mathrm{NaClO}_{4}$ molar concentrations.

3.1.3. Transport properties as a function of the electrolyte concentration. The ion-solvent interactions in the electrolytes were investigated through their transport properties, such as viscosity, ionic conductivity, and diffusion. The behavior of these properties can provide information about the effectiveness of the electrolyte concentration in energy storage devices. Viscosity $(\eta)$ was calculated using the Green-Kubo formula by integrating the autocorrelation function of elements outside the diagonal of the pressure tensor: ${ }^{27,38}$

$$
\eta=(\mathrm{V} / \mathrm{k} \text { B T }) \int_{0}^{\infty} P_{\alpha \beta}(t) P_{\alpha \beta}(0) \mathrm{d} t \quad \text { where } \alpha, \beta=x, y, z
$$

Fig. 7 shows the shear viscosity for each $\mathrm{NaClO}_{4}$ concentration (red curve). As expected, the shear viscosity increases 


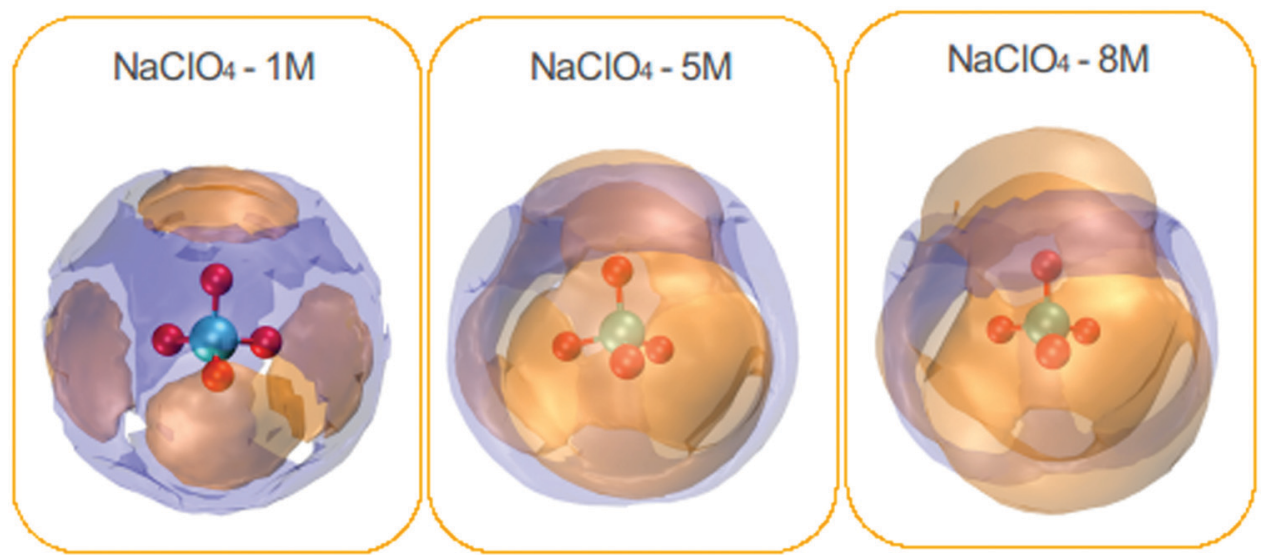

Fig. 6 Spatial density functions (SDF) of the neighboring water molecules (purple surface) and $\mathrm{Na}^{+}$ions (orange surface) around the $\mathrm{ClO}_{4}{ }^{-}$species. $\mathrm{NaClO}_{4}$ concentrations: 1,5 , and $8 \mathrm{M}$.

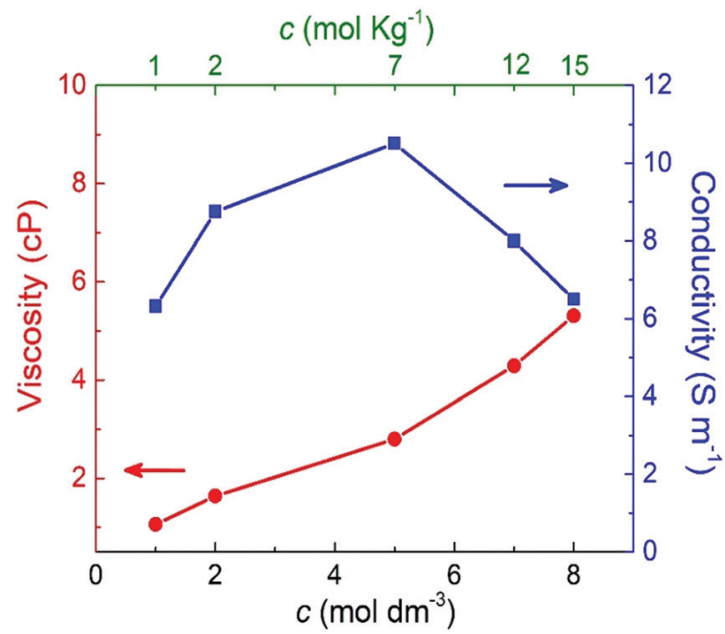

Fig. 7 Shear viscosity and ionic conductivity as a function of the molar and molal concentrations of $\mathrm{NaClO}_{4}$ aqueous solutions.

(almost linearly) with molar concentration. This behavior also has been experimentally observed by $\mathrm{Bu}$ and co-workers. ${ }^{10}$ Here, from $1 \mathrm{M}$ to $8 \mathrm{M}$ is reported a rise of $80 \%$ in viscosity. The increase of viscosity may be related to the shift of the band of stretching of the ion $\mathrm{ClO}_{4}{ }^{-}\left(v_{1}\right)$, which implies the formation of ionic pairs and ionic aggregates (CIP/AG) in solution. (Please see further discussion on Raman analysis of electrolyte.) This way, the formation of CIP/AG affects viscosity as well as ionic mobility; furthermore, this may be the possible cause for the formation of SBI. ${ }^{13}$

The Einstein-Helfand method was applied for the ionic conductivity calculations, which is based on the linear slope of the mean displacement of the collective translational dipole moments $\left(M_{j}\right):^{27}$

$$
\lim _{t \gg t_{\mathrm{c}}}\left\langle\Delta M_{j^{2}}(t)\right\rangle=\left[6 V k_{\mathrm{B}} T \sigma\right]+2\left\langle\Delta M_{j^{2}}\right\rangle
$$

The blue curve in Fig. 7 indicates that the ionic conductivity reaches its maximum value of $10.5 \mathrm{~S} \mathrm{~m}^{-1}$ at $5 \mathrm{M}$ (or 7 molal).
A minimum conductivity of $6.5 \mathrm{~S} \mathrm{~m}^{-1}$ was verified for the minimum ( $1 \mathrm{M}$ ) and maximum ( $8 \mathrm{M}$ or 15 molal) concentrations. These results point out that a concentration above $5 \mathbf{M}$ (or 7 molal) negatively impacted ionic conductivity. This profile is in agreement with the experimental findings reported by R. Sakamoto et al. ${ }^{5}$ who observed a decrease of $\mathrm{NaClO}_{4}$ ionic conductivity above $7 \mathrm{~mol} \mathrm{~kg}^{-1}$.

These findings highlight the significant difference between SiWE and WiSE. It is well-known that highly diluted ionic solutions follow Walden's rule, which establishes that the limiting molar conductance $\left(\lambda_{\mathrm{m}}^{0}\right)$ is inversely proportional to viscosity $\left(\eta^{0}\right) .{ }^{50}$ In the case of $\mathrm{NaClO}_{4}$ aqueous solutions, $\lambda_{\mathrm{m}}^{0} \times \eta \approx 1.17$ in the $283-313 \mathrm{~K}$ interval. Also, diluted SiWE follows the Debye-Hückel-Onsager theory given by equation $\Lambda_{m}=\Lambda_{\mathrm{m}}^{0}-\left(A+B \Lambda_{\mathrm{m}}^{0}\right) c^{1 / 2}$, where $\Lambda_{m}=$ $\Lambda / m$, and $A$ and $B$ are empirical constants for a particular electrolyte solution. In this work, it has been confirmed that the molal conductivity is given by the correlation $\Lambda_{m}=0.46+$ 7.35exp $(-0.304 m)$ (please see Fig. S2 and S3, ESI $\dagger$ ).

Yin et al. ${ }^{41}$ reported experimentally that for $\mathrm{NaClO}_{4}$ concentrations in the range of 0.1 to $5 \mathrm{M}$, the supercapacitors using a $5 \mathrm{M}$ solution showed higher ionic conductivity and specific capacitance among all the analyzed concentrations.

As the last analysis is concerned with the ionic mobility assessed by the diffusion coefficients $(D)$, the latter parameter can be evaluated from the linear adjustment of the mean quadratic displacement of $r_{\mathrm{i}}:{ }^{27}$

$$
D=\frac{1}{6} \lim _{t \rightarrow \infty}\langle|r(t)-r(0)|\rangle^{2}
$$

Fig. 8 compares the ionic diffusion coefficient for water, $\mathrm{Na}^{+}$, and $\mathrm{ClO}_{4}{ }^{-}$. As expected, the diffusion coefficients decrease as a function of the electrolyte concentration. This tendency is in agreement with the previous experimental studies reported by Heil et al. ${ }^{51}$

For all cases, water presents higher diffusivity than the ions by $\sim 50 \%$. The water diffusion coefficient decreased from $1.90 \times 10^{-5}$ to $0.73 \times 10^{-5} \mathrm{~cm}^{2} \mathrm{~s}^{-1}$ when the concentration increased from 1 to $8 \mathrm{M}$, respectively. This reduction is related 


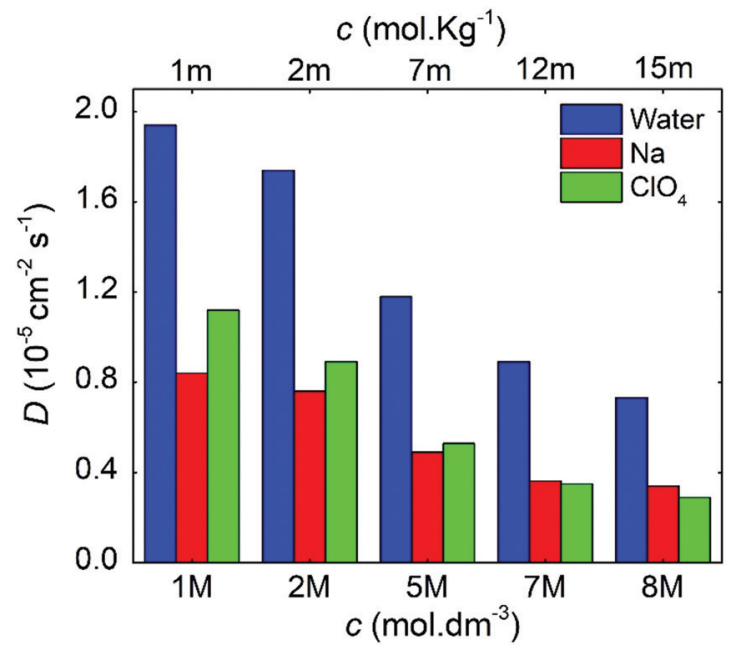

Fig. 8 Diffusion coefficients as a function of the molal and molar concentrations for the $\mathrm{NaClO}_{4}$ aqueous electrolytes.

to a molar ratio decrease from 55.0 to 6.9 , which impacts directly on the mobility of the different solution species. ${ }^{38,52}$ All ions followed a similar trend, but it is worth mentioning that for $7 \mathrm{M}$, the diffusion of $\mathrm{ClO}_{4}{ }^{-}$became lower when compared to that of $\mathrm{Na}^{+}$. The $\mathrm{ClO}_{4}{ }^{-}$diffusion is affected by the reduction in ionic mobility at higher concentrations and its relative size compared to $\mathrm{Na}^{+}$.

Generally, the MD simulation findings revealed that all investigated electrolyte properties (e.g., energetic, structural, and transport) depend on the $\mathrm{NaClO}_{4}$ concentration. These findings are in agreement with the literature. ${ }^{5,41}$ Several studies have reported the advantages of using WiSE for expanding the ESW in SCs. ${ }^{8,10,21,53}$ However, as the MD results suggested, this advantage does not come from any specific properties of electrolytes, especially concerning viscosity and ionic conductivity. These properties have a prominent role in the bulk electrolyte characteristics. On the contrary, spanning the ESW also depends on the charge-transfer kinetics at the electrode/solution interface. As will be seen, interesting findings were obtained in the electrochemical studies.

\subsection{Experimental results}

3.2.1. Raman analysis of electrolyte. Fig. 9 shows Raman spectra of the electrolytes used in the fabrication of the supercapacitors. Fig. 9(a) shows the bands associated with the 4 characteristic vibrational modes of the $\mathrm{ClO}_{4}{ }^{-}$anion. At $462.7 \mathrm{~cm}^{-1}$ and $632 \mathrm{~cm}^{-1}$ are the bands linked to the symmetric $\left(\nu_{2}\right)$ and asymmetric $\left(\nu_{4}\right)$ bending modes, which do not show important changes with increasing the concentration. Between $1030 \mathrm{~cm}^{-1}$ and $1195 \mathrm{~cm}^{-1}$ is the band corresponding to the asymmetric mode of stretching $\left(\nu_{3}\right)$ which is wide and weak, and like the previous ones, it is not affected by the change in concentration. ${ }^{54}$ The most intense band associated with the symmetric stretch mode $\left(\nu_{1}\right)$ is centered at $\sim 938 \mathrm{~cm}^{-1}$, and shows notable characteristics such as a marked asymmetry in its shape and a blue shift linked to the change in electrolyte concentration. $^{55}$ These remarkable characteristics show changes in the electrolyte structure as already discussed in Section 3.1.2. Upon the detailed study of the band $\left(\nu_{1}\right)$, its decomposition in three sub-bands, linked to different coordination states of the anion with the water molecules and eventually with the cation can be observed (see inset of Fig. 9(a)). ${ }^{5,56}$

The sub-band located in the low-frequency region (ca. $928.8 \mathrm{~cm}^{-1}$ ) is related to the presence of free anions in solution (henceforth FA). A second band, ascribed to solvent separated ion pairs (SSIP), occurs at $937.6 \mathrm{~cm}^{-1}$ for the electrolyte of concentration $7 \mathrm{~m}$ and then shifts to $939.6 \mathrm{~cm}^{-1}$ for the concentration $15 \mathrm{~m}$. The band located at $943.4 \mathrm{~cm}^{-1}$ that appears in the WiSE concentration is associated with the changes in the solvation layers of the anion due to coordination with the cation, forming contact ion pairs and ionic aggregates (CIP/AG). It is remarkable how the intensity of the sub-band of free anions decreases with increasing concentration, confirming the results obtained by simulation presented in Fig. 5 and 6. Fig. 9(b) clearly shows the change in the activity of the water molecules with increasing concentration. The bands associated with the vibrational stretching modes symmetric $\left(\sim 3243 \mathrm{~cm}^{-1}\right)$ and asymmetric $\left(\sim 3413 \mathrm{~cm}^{-1}\right)$ fade dramatically at the same
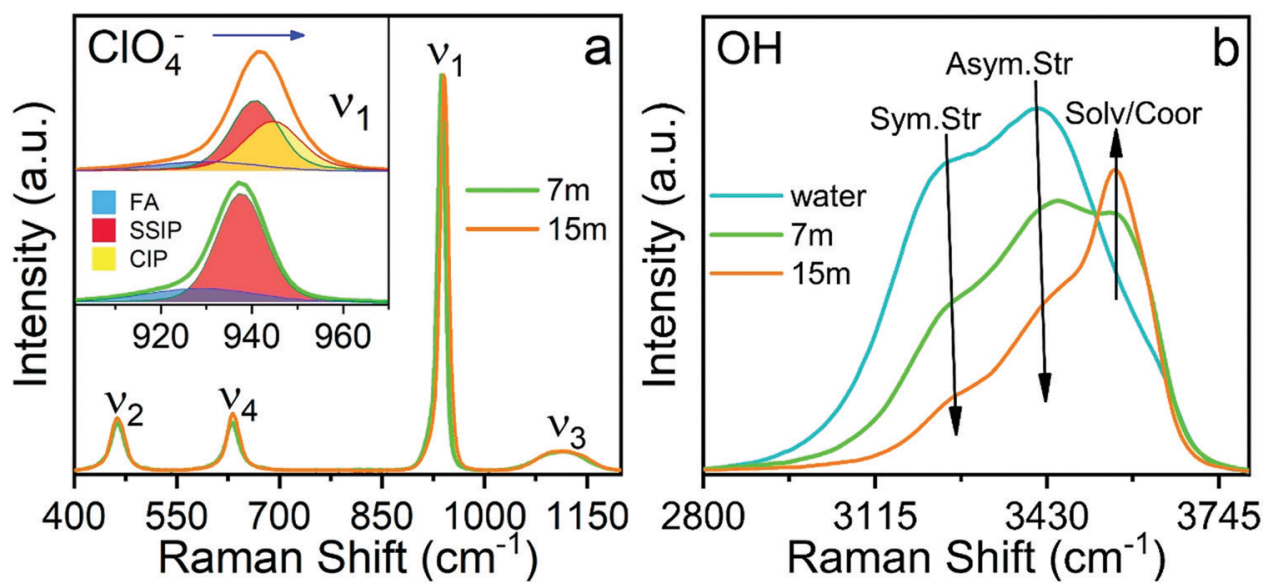

Fig. 9 Raman analysis of electrolytes. (a) Bands of the perchlorate anion. (b) Bands of group $\mathrm{O}-\mathrm{H}$. 
time when a band emerges in the high-frequency region related in the previous studies with the coordination of the water around the cation, which from our point of view is only partially true, since it does not take into account that at high concentrations there is a considerable population of CIP/AG which would indicate that the band $\left(\sim 3555 \mathrm{~cm}^{-1}\right)$ should be associated with the presence of water molecules around the aggregates and ionic pairs. ${ }^{5}$ The formation of CIP/AG and the modification in the environment and the activity of the water molecules, shown by the results of the Raman analysis, confirm the behavior predicted by the computational analysis. As shown in Fig. 4, the total density of hydrogen bonds decreases with increasing concentration, which is due not only to the decrease in the number of water molecules, but also to the effect that the anion has on the network of such links. As the concentration increases, the anions are surrounded by a greater number of water molecules in two different configurations. The first configuration is that of separated solvated ions and the second as solvation layers of CIP/AG. Additionally, the formation of ionic pairs and aggregates can be explained from the computational results, with what is presented in Fig. 3(b) and in Fig. 6, since the increase in cohesive energy is directly related to the increase in molecular interactions, which is expressed as an increase in cation density around $\mathrm{ClO}_{4}^{-}$.

3.2.2. Electrochemical analysis of the SiWE- and WiSE-based supercapacitors. Fig. 10 shows the different electrochemical findings obtained using cyclic voltammetry (CV), single-step chronoamperometry (SSC), and electrochemical impedance spectroscopy (EIS) techniques for a symmetric coin cell as a function of the electrolyte concentration. First, the electrochemical behavior of a $7.0 \mathrm{~mol} \mathrm{~kg}{ }^{-1} \mathrm{NaClO}_{4}$ solution is investigated where the applied voltage was increased from 1.2 to $1.7 \mathrm{~V}$ using a scan rate of $1 \mathrm{mV} \mathrm{s}^{-1}$. As seen in Fig. 10(a1) and (a2), the anodic current departed from an almost constant value of $\approx 12 \mathrm{~mA} \mathrm{~g}^{-1}$ and increased until $\approx 40$ and $24 \mathrm{~mA} \mathrm{~g}^{-1}$, respectively. In principle, these findings indicate the onset of the water-splitting at intermediate $(1.2<U<1.7)$ voltages. Therefore, following the methodology proposed by Nunes et al., ${ }^{33}$ the SSC and EIS techniques were applied to correctly determine the maximum for the electrochemical stability window (ESW) as a function of the electrolyte concentration.

For the different molalities $\left(\mathrm{m} / \mathrm{mol} \mathrm{kg}^{-1}\right)$, the $\mathrm{CV}$ findings showed an almost ideal electrical double-layer capacitance (EDLC) behavior characterized by symmetric rectangular voltammetric profiles up to $U \approx 1.3 \mathrm{~V}$. The upward anodic current following an exponential trend verified at $c a . U>1.3 \mathrm{~V}$ denounces the onset of electrolyte decomposition, as predicted by the well-known Butler-Volmer's model $\left(I_{\mathrm{f}} \cong I_{0} \exp (\alpha F \eta / R T)\right.$, when $\eta>0.1 \mathrm{~V}$ ), which represents the electron transfer kinetics at the electrode/electrolyte interface. In the model, $\eta \equiv U-$ $1.23 \mathrm{~V}$ is the overpotential for water-splitting, while the 'kinetic parameters' are the exchange current density $\left(I_{0}\right)$ and the charge-transfer (or symmetry) coefficient $(\alpha)$. As is already known $F$ is the Faraday constant, $R$ is molar gas constant and
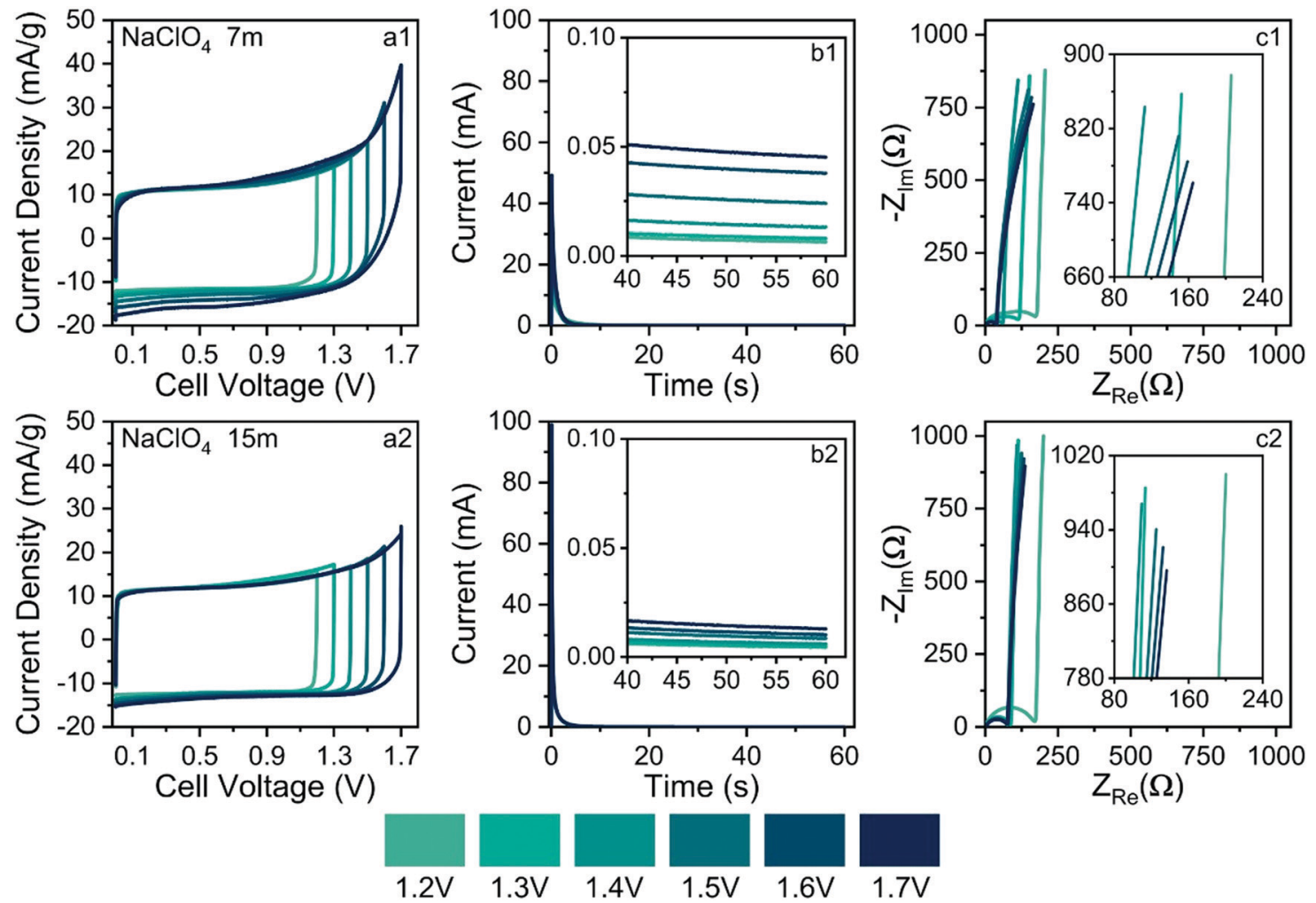

Fig. 10 Electrochemical findings obtained using the CV (a), SSC (b), and EIS (c) techniques. Conditions: (a-c)(1) $7.0 \mathrm{~mol} \mathrm{~kg}^{-1} \mathrm{NaClO}_{4}$, and (a-c)(2) $15.0 \mathrm{~mol} \mathrm{~kg}{ }^{-1} \mathrm{NaClO}_{4} . \nu=1 \mathrm{mV} \mathrm{s}^{-1}$. Electrode: MWCNTs. 
$T$ is the absolute temperature. At low scan rates (e.g., $\nu \leq$ $1 \mathrm{mV} \mathrm{s}^{-1}$ ), the faradaic current $\left(I_{\mathrm{f}}\right)$ is large compared to the capacitive current $\left(I_{\mathrm{c}}=C_{\mathrm{edl}} \nu\right)$ since the former current does not depend on the voltage scan rate $(\nu)$. Therefore, the $\mathrm{CV}$ technique alone is not recommended to determine the maximum ESW in SCs. ${ }^{33}$ Unfortunately, in several cases, the maximum ESW values are incorrectly evaluated at high scan rates leading to misleading findings since the faradaic current due to water-splitting can be masked by the capacitive current.

As commented in the Introduction section, highly concentrated electrolytes typically reduce the onset of the water-splitting reaction. In this sense, Fig. 10(b1) and (b2) show the SSC findings (e.g., current transients \& residual currents) for the different applied voltages and electrolyte concentrations. The analysis of current transients makes it possible to discriminate the capacitive and faradaic responses. ${ }^{33}$ For wellbehaved SCs, the transient capacitive current $\left(I_{\mathrm{c}}\right)$ is given by the relation $I_{\mathrm{c}}=\left(\delta U / R_{\mathrm{ESR}}\right) \exp \left(-t / R_{\mathrm{ESR}} \times C_{\mathrm{CDE}}\right)$, where $\delta U$ is the applied voltage step, $R_{\mathrm{ESR}}$ is the equivalent series resistance, $C_{\mathrm{CDE}}$ is the capacitance of the device, and $\left(\delta U / R_{\mathrm{ESR}}\right) \equiv I_{(t \rightarrow 0)}$ is the initial current measured at $t=0$. For most laboratory-made coin cell devices, which exhibit a small time constant $\left(\tau=R_{\mathrm{ESR}}\right.$ $\left.\times C_{\mathrm{CDE}}\right)$, the capacitive current must practically fade away, corresponding to a current reduction $\left(\right.$ e.g.,$\left.I_{\mathrm{c}} / I_{(t \rightarrow 0)} \times 100 \%\right)$ of $c a .99 .9 \%$, after $\approx 10-20 \mathrm{~s}$. Therefore, the verification of nonnegligible stationary (residual) currents $(\geq 0.1 \%)$ in the SSC experiments indicates the occurrence of water-splitting.

From the above considerations, current transients were recorded up to $60 \mathrm{~s}$ to determine the magnitude of the residual current at $t>10 \mathrm{~s}$. In the case of Fig. 10(b1) and b(2), current reductions of $0.1 \%$ and $0.025 \%$, respectively, were observed for different electrolytes at $1.7 \mathrm{~V}$. Therefore, in light of the SSC experiments, one can discard the occurrence of water-splitting in the case of the $15.0 \mathrm{~mol} \mathrm{~kg}^{-1} \mathrm{NaClO}_{4}$ (WiSE) solution. In the case of the SiWE $\left(7.0 \mathrm{~mol} \mathrm{~kg}^{-1} \mathrm{NaClO}_{4}\right)$ system, additional evidence obtained from the EIS technique is necessary to discriminate the occurrence of water-splitting at very low current levels.

The analysis of the low-frequency data in the complex-plane plots gives information regarding the occurrence of watersplitting. Thus, EIS findings were obtained applying the same voltages used in the CV and SSC experiments. Deviations from the linearity $\left(r^{2}<0.997\right)$ verified in the complex-plane plot at low frequencies $(f \leq 1 \mathrm{~Hz})$ confirm the presence of watersplitting since the impedance response is no longer purely capacitive. Indeed, the presence of a charge-transfer resistance $\left(R_{\mathrm{CT}}\right)$ in parallel to the electrical double-layer charging process $\left(C_{\mathrm{DCL}}\right)$ results in a poorly developed semicircle at low frequencies that can be identified using the complex non-linear least squares (CNLS) method of simulation.

Fig. 10(c1) and (c2) show the complex-plane plots for the $\mathrm{NaClO}_{4}$-based SCs at different voltages. Generally, well-behaved SCs are characterized by low-frequency phase angles $(\varphi)$ greater than $c a .-83^{\circ}$, i.e., from the perspective of the constant phase element (CPE) approach, used to represent the frequency dispersion phenomenon intrinsic to solid electrodes, where
$Z_{\text {cpe }}=1 / Y_{0}(j \omega)^{n}$; a good SC behavior is associated with ca. $n>$ 0.95 where $Y_{0} \cong C_{\text {edl }}$. Obviously, the unit of a true capacitance is the farad ( $F \equiv \mathrm{s} \Omega^{-1}$ ), while in the case of a CPE, one has the fractal unity given by $F \mathrm{~s}^{n-1}$. The conversion between $Y_{0}$ and $C_{\text {edl }}$ can be done using the Brug-Sluyters' formula.

In the case of data shown Fig. 10(c1), the linear regression analysis using the $R-\mathrm{CPE}$ circuit model revealed an excellent linear correlation only for $U \leq 1.4 \mathrm{~V}$. Therefore, the maximum ESW value in the case of the SiWE system is $1.4 \mathrm{~V}$. On the contrary, in the WiSE system, the impedance analysis confirmed the maximum ESW value of $1.6 \mathrm{~V}$.

In principle, the electrochemical findings were in agreement with the energetic and structural properties extracted from MD simulations, where the formation of an SBI structure is predicted for WiSE systems. Since SiWE has high ionic conductivity and many free water molecules compared to WiSE, the former system does not form an SBI structure. Therefore, the water molecules in the case of SiWE directly interact with the electrode's surface at high voltages (e.g., strong electric fields of $\approx 10^{7} \mathrm{~V} \mathrm{~cm}{ }^{-1}$ ), permitting the occurrence of charge-transfer kinetics accounting for water-splitting. After all, the lower diffusivity of water molecules in highly concentrated electrolytes reflects a decreased ionic mobility, formation of a solid barrier interface, or the presence of an SBI structure. As a result, the charge-transfer (faradaic) reaction was strongly inhibited at higher voltages for the WiSE system.

Fig. 11 shows the findings obtained from the galvanostatic charge-discharge experiments.

The ESW values previously determined in this study were applied in the GCD experiments. As seen in Fig. 11, the GCD curves are linear as expected for well-behaved EDLCs. The applied current densities from 0.25 to $4 \mathrm{~A} \mathrm{~g}^{-1}$ affected the different electrochemical parameters. For the SiWE system, the ESR values changed from 84.8 to $83.7 \Omega$ with a maximum relative variation (r.v.) of $1.3 \%$. At the same time, the specific capacitance $\left(C_{\mathrm{s}}\right)$ decreased from 11.9 to 10.5 to $\mathrm{F} \mathrm{g}^{-1}$ (r.v. = $13.3 \%)$. In the case of the WiSE system, the corresponding changes were 143 to $87 \Omega($ r.v. $=64.4 \%)$ and 12.4 to 11.2 to $\mathrm{F} \mathrm{g}^{-1}$ (r.v. $=10.7 \%$ ), respectively.

As seen, there was a significant increase in ESR when the electrolyte concentration was increased from 7.0 to $15 \mathrm{~mol} \mathrm{~kg}^{-1}$. According to the present MD simulations, higher ESR values are indeed expected for WiSE, i.e., highly concentrated solutions have reduced ionic mobility (conductivity) due to the strong degree of ionic association caused by the short- and long-range coulombic interactions, as well as the lower availability of the free solvent molecules. On the contrary, the specific capacitance was not strongly affected by the molality, probably due to a facile insertion of the ionic species into carbon mesopores. In this sense, specific capacitance is less affected by molality since the interface charge-storage process is directly related to the electrochemically active surface area where the carbon mesoporous structures have a relatively large dimension compared to the ion sizes. Therefore, one can propose that the $\mathrm{NaClO}_{4}$-based WiSE increased the ESR but with less pronounced effects on the interfacial phenomenon (double-layer capacitance). In fact, as 

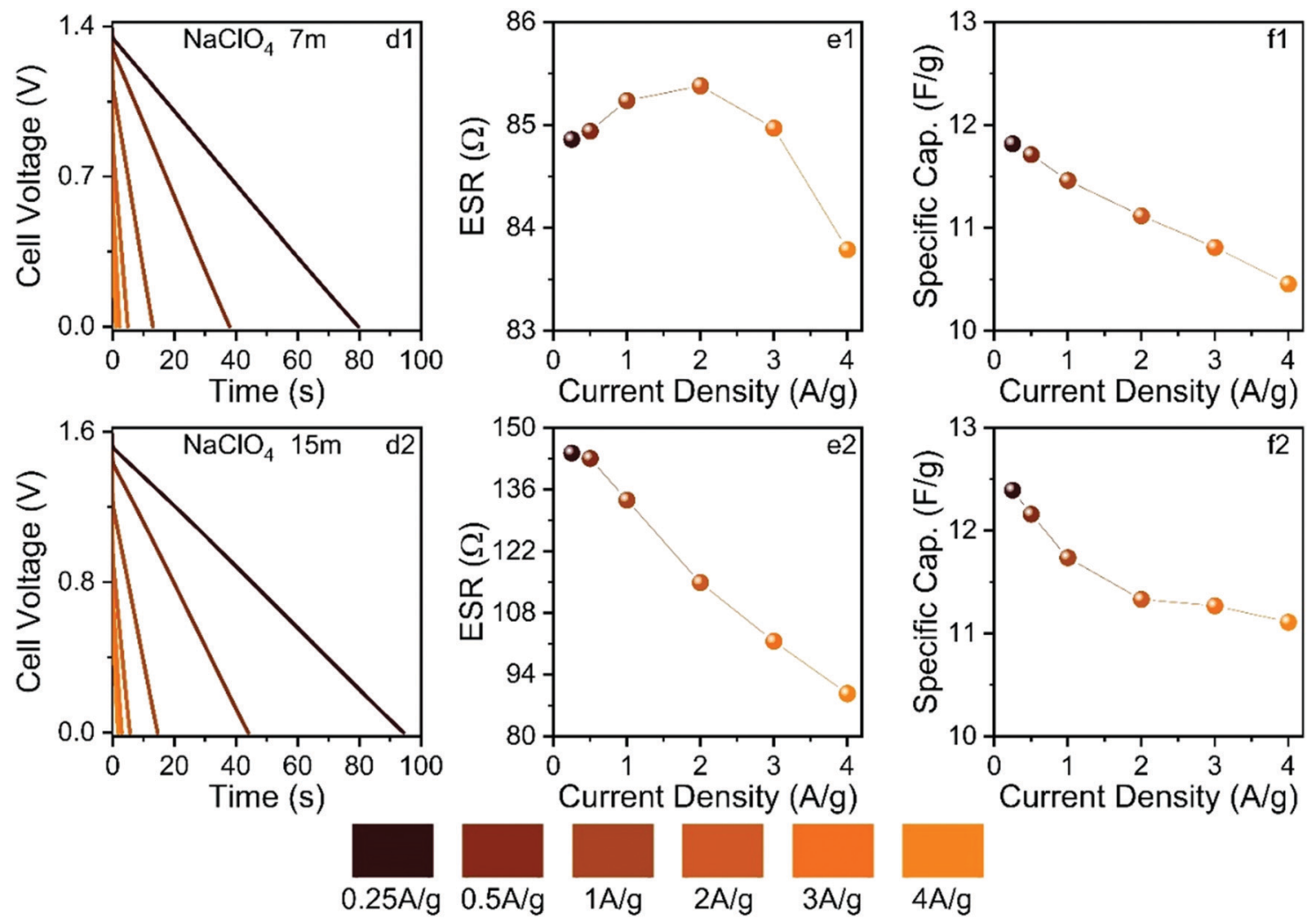

Fig. 11 Findings from the galvanostatic charge-discharge experiments obtained for (1) $7 \mathrm{~mol} \mathrm{~kg}^{-1}$ and (2) $15 \mathrm{~mol} \mathrm{~kg}^{-1} \mathrm{NaClO}_{4}$ aqueous solutions. Plots: (d1 \& d2) discharge curves, (e1 \& e2) equivalent series resistance, and (f1 \& f2) specific capacitance as a function of the applied current density in the range of $0.25 \mathrm{~A} \mathrm{~g}^{-1}$ to $4 \mathrm{~A} \mathrm{~g}^{-1}$. Electrode: MWCNTs.

briefly mentioned in the Introduction section, the major influence of molality on the electrical double-layer behavior is due to local changes in the dielectric constant.

The specific energy $E_{\mathrm{S}}\left(\mathrm{W} \mathrm{h} \mathrm{kg}{ }^{-1}\right)$ and power $P_{\mathrm{s}}\left(\mathrm{W} \mathrm{kg}^{-1}\right)$ of SCs were calculated from the ESR and $C_{\mathrm{s}}$ values. ${ }^{57}$ Fig. 12 shows the Ragone plot obtained for the SiWE and WiSE systems. As can be seen, the use of $\mathrm{NaClO}_{4}$-based WiSE promoted a relative increase of $\sim 38 \%$ for the specific energy and power.

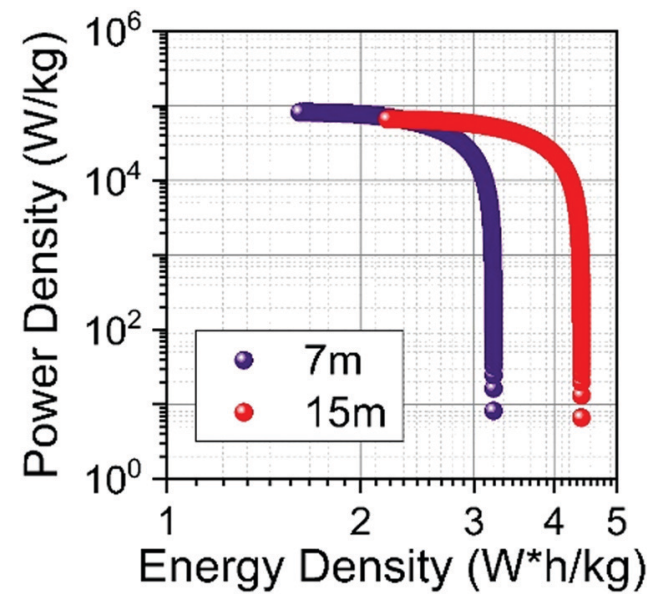

Fig. 12 Ragone plot for symmetrical supercapacitors filled with SiWE (7 $\left.\mathrm{mol} \mathrm{kg}{ }^{-1}\right)$ and WiSE $\mathrm{NaClO}_{4}\left(15 \mathrm{~mol} \mathrm{~kg}^{-1}\right)$ solutions. Electrodes: MWCNTs.
Therefore, the increase verified for ESR is compensated by the large ESWs found in highly concentrated solutions (see Fig. 10).

\section{Conclusions}

We have reported the energetic, structural, and dynamic properties of aqueous electrolytes based on sodium perchlorate $\left(\mathrm{NaClO}_{4}\right)$ in two regimes: conventional (SiWE) and highly concentrated (WiSE), by atomistic molecular dynamics simulations and experimental approaches. Our results clarify the differences between SiWE and WiSE. We have seen that densities and cohesive energies vary dramatically with increasing concentration from $1 \mathrm{~mol} \mathrm{dm} \mathrm{dm}^{-3}\left(1 \mathrm{~mol} \mathrm{~kg}^{-1}\right)$ to $8 \mathrm{~mol} \mathrm{dm}^{-3}$ (15 mol kg-1). Furthermore, at the same concentrations mentioned above, the structural properties showed significant differences, especially about the coordination of the $\mathrm{Na}^{+}-\mathrm{O}_{\mathrm{Cl}}$ ion pairs, which increased by a factor of five. These results were confirmed by the analysis of the spatial distribution functions, which shows an increased sodium coordination around the perchlorate anion as the concentration increases and also by the Raman spectra analyses that show that the said increase in anion-cation coordination is due to the formation of contact ion pairs and ionic aggregates. Thermodynamic properties are usually susceptible to variation in concentration, and our results have confirmed that. The viscosity suffered a significant variation, going from $1.06 \mathrm{cP}$ at $1 \mathrm{~mol} \mathrm{dm}^{-3}$ to $5.31 \mathrm{cP}$ at 
$8 \mathrm{~mol} \mathrm{dm}^{-3}$. The ionic conductivity increases to a maximum at $10.5 \mathrm{~S} \mathrm{~m}^{-1}$ for the $5 \mathrm{~mol} \mathrm{dm}^{-3}$, and then decreasing again, reaching $6.5 \mathrm{~S} \mathrm{~m}^{-1}$ at $8 \mathrm{~mol} \mathrm{dm}^{-3}$. Both results for viscosity and conductivity are directly linked to ionic mobility, which is measured by the diffusion coefficient and has also been significantly reduced with increasing concentration. Our results indicate WiSE does not have typical properties expected for an aqueous electrolyte (for example, low viscosity and high conductivity). We observed WiSE has higher density and viscosity and lower ionic conductivity. These findings come from the strong degree of ionic association caused by the shortand long-range coulombic interactions, as well as lower availability of the free solvent molecules which increase the ESR. Nonetheless, we have noted that WiSE electrolytes presented increase the ESW and consequently cell's energy density. Such expansion is possible because solvent blocking interface blocks water to contact polarized electrode i.e., all available water molecules are solvating structure of both ions $\left(\mathrm{ClO}_{4}{ }^{-}\right.$and $\left.\mathrm{Na}^{+}\right)$, that decrease the hydrogen bonds between the water molecules, generating a perfect environment for the formation of SBI. In addition, we found that the specific capacitance was not strongly affected by the molality, which may be related to the relatively large dimension of carbon mesoporous structures that make the insertion of the ionic species into carbon mesopores easy. In conclusion, the results presented here provide a better understanding of the advantages and disadvantages of using WiSE electrolytes in supercapacitors in light of their energy, structural and transport properties.

\section{Conflicts of interest}

There are no conflicts to declare.

\section{Acknowledgements}

The authors are very grateful for the financial support from the Brazilian funding agencies CAPES (PROEX 88887.374731/2019-00 and Print-CAPES (8887.572651/2020-00)), and São Paulo Research Foundation - FAPESP (2017/11958-1 \& 2014/02163-7). L.M. Da Silva wishes to thank the Minas Gerais Research Foundation FAPEMIG. H. Zanin and L. M. Da Silva wish to thank the National Council for Scientific and Technological Development - CNPq for the PQ-2 grant (310544/2019-0). The authors gratefully acknowledge the financial support from Shell and the strategic importance of the support given by ANP (Brazil's National Oil, Natural Gas, and Biofuels Agency) through the R\&D levy regulation.

\section{References}

1 D. Larcher and J. M. Tarascon, Nat. Chem., 2015, 7, 19-29. 2 J. B. Goodenough and Y. Kim, Chem. Mater., 2010, 22, 587-603. 3 B. Scrosati and J. Garche, J. Power Sources, 2010, 195, 2419-2430.
4 V. Etacheri, R. Marom, R. Elazari, G. Salitra and D. Aurbach, Energy Environ. Sci., 2011, 4, 3243-3262.

5 R. Sakamoto, M. Yamashita, K. Nakamoto, Y. Zhou, N. Yoshimoto, K. Fujii, T. Yamaguchi, A. Kitajou and S. Okada, Phys. Chem. Chem. Phys., 2020, 22, 26452-26458.

6 A. Ponrouch, D. Monti, A. Boschin, B. Steen, P. Johansson and M. R. Palacín, J. Mater. Chem. A, 2015, 3, 22-42.

7 D. Monti, E. Jónsson, A. Boschin, M. R. Palacín, A. Ponrouch and P. Johansson, Phys. Chem. Chem. Phys., 2020, 22, 22768-22777.

8 K. Nakamoto, R. Sakamoto, M. Ito, A. Kitajou and S. Okada, Electrochemistry, 2017, 85, 179-185.

9 H. Kim, J. Hong, K. Y. Park, H. Kim, S. W. Kim and K. Kang, Chem. Rev., 2014, 114, 11788-11827.

10 X. Bu, L. Su, Q. Dou, S. Lei and X. Yan, J. Mater. Chem. A, 2019, 7, 7541-7547.

11 R.-S. Kühnel, D. Reber and C. Battaglia, J. Electrochem. Soc., 2020, 167, 070544.

12 L. Suo, Y. S. Hu, H. Li, M. Armand and L. Chen, Nat. Commun., 2013, 4, 1-9.

13 P. Kulkarni, D. Ghosh and G. Balakrishna, Sustainable Energy Fuels, 2021, 5, 1619-1654.

14 J. W. Morales, H. R. Galleguillos, F. Hernández-Luis and R. Rodríguez-Raposo, J. Chem. Eng. Data, 2011, 56, 3449-3453.

15 G. J. Janz, B. G. Oliver, G. R. Lakshminarayanan and G. E. Mayer, J. Phys. Chem., 1970, 74, 1285-1289.

16 J. Braunstein, J. Phys. Chem., 1967, 71, 3402-3407.

17 R. H. Stokes and R. A. Robinson, J. Am. Chem. Soc., 1948, 70, 1870-1878.

18 D. Reber, R. S. Kühnel and C. Battaglia, Sustainable Energy Fuels, 2017, 1, 2155-2161.

19 L. Jiang, L. Liu, J. Yue, Q. Zhang, A. Zhou, O. Borodin, L. Suo, H. Li, L. Chen, K. Xu and Y. S. Hu, Adv. Mater., 2020, 32, 1-10.

20 L. Suo, O. Borodin, Y. Wang, X. Rong, W. Sun, X. Fan, S. Xu, M. A. Schroeder, A. V. Cresce, F. Wang, C. Yang, Y. S. Hu, K. Xu and C. Wang, Adv. Energy Mater., 2017, 7, 1-10.

21 K. Nakamoto, R. Sakamoto, Y. Sawada, M. Ito and S. Okada, Small Methods, 2019, 3, 1-5.

22 M. Chen, G. Feng and R. Qiao, Curr. Opin. Colloid Interface Sci., 2020, 47, 99-110.

23 L. Martínez, R. Andrade, E. G. Birgin and J. M. Martínez, J. Comput. Chem., 2009, 30, 2157-2164.

24 W. L. Jorgensen, D. S. Maxwell and J. Tirado-Rives, J. Am. Chem. Soc., 1996, 118, 11225-11236.

25 J. L. F. Abascal and C. Vega, J. Chem. Phys., 2005, 123, 1-12.

26 K. Nieszporek, P. Podkościelny and J. Nieszporek, Phys. Chem. Chem. Phys., 2016, 18, 5957-5963.

27 K. Nieszporek, J. Nieszporek and M. Trojak, Comput. Theor. Chem., 2016, 1090, 52-57.

28 M. Parrinello and A. Rahman, J. Appl. Phys., 1981, 52, 7182-7190.

29 G. J. Martyna, M. L. Klein and M. Tuckerman, J. Chem. Phys., 1992, 97, 2635-2643.

30 T. Darden, D. York and L. Pedersen, J. Chem. Phys., 1993, 98, 10089-10092. 
31 M. J. Abraham, T. Murtola, R. Schulz, S. Páll, J. C. Smith, B. Hess and E. Lindah, SoftwareX, 2015, 1-2, 19-25.

32 M. M. Amaral, M. J. Pinzón C., A. C. Peterlevitz, C. A. Rufino Júnior, L. M. Da Silva and H. Zanin, Diam. Relat. Mater., 2021, 115, 108354.

33 W. G. Nunes, B. G. A. Freitas, R. M. Beraldo, R. M. Filho, L. M. Da Silva and H. Zanin, Sci. Rep., 2020, 10, 1-9.

34 D. Baowan, B. J. Cox, T. A. Hilder, J. M. Hill and N. Thamwattana, Modelling and Mechanics of Carbon-Based Nanostructured Materials, Elsevier, Oxford, 2017.

35 A. Noori, M. F. El-Kady, M. S. Rahmanifar, R. B. Kaner and M. F. Mousavi, Chem. Soc. Rev., 2019, 48, 1272-1341.

36 S. Zhang and N. Pan, Adv. Energy Mater., 2015, 5, 1-19.

37 T. R. Kartha and B. S. Mallik, Mater. Today Commun., 2020, 25, 101588.

38 P. Inoue, E. Fileti and T. Malaspina, J. Phys. Chem. B, 2020, 124, 5685-5695.

39 K. R. J. Lovelock, R. Soc. Open Sci., 2017, 4, 171223.

40 Q. Dou, Y. Lu, L. Su, X. Zhang, S. Lei, X. Bu, L. Liu, D. Xiao, J. Chen, S. Shi and X. Yan, Energy Storage Mater., 2019, 23, 603-609.

41 J. Yin, C. Zheng, L. Qi and H. Wang, J. Power Sources, 2011, 196, 4080-4087.

42 Y. Chen, Y. H. Zhang and L. J. Zhao, Phys. Chem. Chem. Phys., 2004, 537-542.

43 C. Zhou, Y. Guo, W. Huang, H. Jiang and L. Wu, J. Phys. Conf. Ser., 2017, 916, 12036.
44 C. Argue, "To what degree does temperature impact EV range?," can be found under https:/www.geotab.com/blog/ ev-range/, 2020.

45 G. Heinje, W. A. P. Luck and K. Heinzinger, J. Phys. Chem., 1987, 91, 331-338.

46 S. Varma and S. B. Rempe, Biophys. Chem., 2006, 124, 192-199.

47 I. J. General, E. K. Asciutto and J. D. Madura, J. Phys. Chem. $B, 2008,112,15417-15425$.

48 M. Brehm and B. Kirchner, J. Chem. Inf. Model., 2011, 51, 2007-2023.

49 M. Brehm, M. Thomas, S. Gehrke and B. Kirchner, J. Chem. Phys., 2020, 152, 164105.

50 E. A. Moelwyn-Hughes, Physical Chemistry, Pergamon, New York, 1964.

51 S. R. Heil, M. Holz, T. M. Kastner and H. Weingärtner, J. Chem. Soc., Faraday Trans., 1995, 91, 1877-1880.

52 J. Fiates, Y. Zhang, L. F. M. Franco, E. J. Maginn and G. Doubek, Phys. Chem. Chem. Phys., 2020, 22, 15842-15852.

53 J. Park, J. Lee and W. Kim, ACS Energy Lett., 2021, 6, 769-777. 54 P. Larkin, Infrared and Raman Spectroscopy, Elsevier, 2011. 55 A. G. Miller and J. W. Macklin, J. Phys. Chem., 1985, 89, 1193-1201. 56 M. H. Lee, S. J. Kim, D. Chang, J. Kim, S. Moon, K. Oh, K. Y. Park, W. M. Seong, H. Park, G. Kwon, B. Lee and K. Kang, Mater. Today, 2019, 29, 26-36.

57 R. Vicentini, J. P. Aguiar, R. Beraldo, R. Venâncio, F. Rufino, L. M. Da Silva and H. Zanin, Batter. Supercaps, 2021, 4, 1291-1303. 